\title{
Propulsion Performance Analysis of Wave-Powered Boats
}

\author{
Zong-Yu Chang ${ }^{1,2, *}$, Chao Deng ${ }^{1}$, Jia-Kun Zhang ${ }^{1}$, Zhan-Xia Feng ${ }^{1}$, Zhong-Qiang Zheng ${ }^{1,2}$ \\ ${ }^{1}$ College of Engineering, Ocean University of China, Qingdao, China \\ ${ }^{2}$ Key Lab of Ocean Engineering of Shandong Province, Qingdao, China \\ Received 17 May 2019; received in revised form 21 July 2019; accepted 26 August 2019
}

DOI: https://doi.org/10.46604/ijeti.2020.4276

\begin{abstract}
With the development of oceanographic research and marine environment protection, mobile marine platforms are applied for ocean observation for a long journey. Wave-powered boats are capable of applying wave motion to propel itself and make a long-duration survey. This paper presents the dynamics of the wave-powered boat under the excitation of the heave motion and pitch motion. Taking the wave-powered boat with double fins as an example, the heave and pitch motions of the boat are obtained by ANSYS-AQWA firstly. Then the relationship between propulsion performance and three factors, including wave height, wave period, and restoring stiffness of torsion spring, was analyzed through multibody dynamics software ADAMS. With the increase of sea state from level 1 to level 4 the average propulsion speed increased from $0.4 \mathrm{~m} / \mathrm{s}$ to $1.4 \mathrm{~m} / \mathrm{s}$. Under the same wave height and period, with the increase of restoring stiffness of torsion spring from $0.0125 \mathrm{~N} \cdot \mathrm{m} / \mathrm{deg}$ to $0.3 \mathrm{~N} \cdot \mathrm{m} / \mathrm{deg}$, the propulsion speed of the wave-powered boat increases first and then decreases, and there exists an optimum stiffness. Through the calculation it is found that when the restoring stiffness of torsional spring is increased from $0.025 \mathrm{~N} \cdot \mathrm{m} / \mathrm{deg}$ to $0.2 \mathrm{~N} \cdot \mathrm{m} / \mathrm{deg}$ with the sea state level 1 to 4 , the wave powered boat has better propulsion performance.
\end{abstract}

Keywords: wave-powered boat, dynamics analysis, ADAMS

\section{Introduction}

Ocean mobile observation vehicles play an important part in the ocean stereoscopic observation, which can locate and move according to the operation command and conduct large-area observation. Wave gliders and wave powered boats are two kinds of ocean mobile observation vehicles propelled by wave. A wave-powered boat generates propulsion by the two fins installed on the bow and the stern of boat.

The wave powered boat is not a new invention. In 1898 Linden [1] carried out the patent of ship that was powered by wave energy(as shown in Fig. 1(a)). Jakobsen [2] et al. began to carry out sea trial experiments on wave energy vessels. In addition, he found that the fin fixed at the front of the hull (as shown in Fig. 1(b)) not only increased the forward speed but also enhanced the stability of the hull movement. Terao [3-6] tested the wave fin on a fishing boat (as shown in Fig. 1(c)), and the experimental results show that the speed and stability of the wave fin are obviously improved, he also proposed a new type of WDPS system of catamaran structure, which adopts a dual wing driving structure(as shown in Fig. 1(d)-(e)). In 2008, Kenichi Horie made a trans-pacific voyage from Hawaii to Japan, which was $7800 \mathrm{~km}$ long. This process was completed by using a wave-powered ship designed by Terao [7]. AutoNaut is a commercial wave powered boat (as shown in Fig. 1(f)). The AutoNaut utilizes springloaded flapping foils at the bow and stern to transit the oceans for up to 3 months, and relies on solar energy combined with fuel cells to deliver power for onboard systems (MOST (AV) Ltd 2015).

On numerical simulation, Belibassakis et al. [8-9] carried out the hydrodynamic analysis of flapping fin and analyzed its random fluctuation at a constant forward speed, The results show that within a certain range of motion parameters, the stability

* Corresponding author. E-mail address: zongyuchang@ouc.edu.cn

Tel.: +86-13280858045 
of the ship has been significantly improved. At the same time, it can generate an anti-rolling moment to absorb the vibration. Li et al. [10-12] designed an experimental platform for catamaran and carried out experiments, they made a resistance tests on the boat and compared the results with the ANSYS-AQWA calculation results, at the same time, the self-navigation experiments on the boat in different wave conditions was carried out as well. They also compiled a program to simulate the motion of the boat with experimental data. Zhu et al. [13] used a three-dimensional panel method to predict the motion and drag-increasing response of the prototype and the fin ship in regular waves. They also compared with the experimental results to verify the accuracy of the calculation results. Feng P. Y .et al. [14] established a frequency-domain coupled hydrodynamic model of oscillating fin and large cargo ship in the case of top wave, they analyzed the influence of fin on seakeeping of ship, and studied the influence of installation position of fin, spring stiffness, submergence depth and other parameters on wave energy recovery effect by using the model. Feng [15-16] established the multi-body dynamics model of unmanned vehicles. Tian et al. [17] introduced the structural design of flexible webbed fins, and they studied the motion principle of webbed fins device and established a computational model for the driving force of flexible webbed fins. Simultaneously, a prototype of the principle is built, and the wave-making flume experiment is preliminarily built based on potential flow theory. In K. Suastika's paper [18], effects of the stern-foil submerged elevation on the lift and drag of a fin craft were studied by using Computational Fluid Dynamics (CFD) and considering three alternative stern-foil submerged elevations. J. A. Bowker et al. [19] investigate the relationship between flapping foil propulsion and power generation in the context of ASVs. H. Yamaguchi et al. [20] studied the influence of parameters related to fin propulsion on propulsion speed. F. C. Chiu et al. [21] investigate the feasibility of a concept using an active pitch-oscillating fin to harness wave power for propulsion enhancement of merchant ships. Experimental data of the NACA 0012 oscillating foil was adopted to validate the present CFD simulation. S. W. Huang et al. [22] proposed an effective energy-saving device to extract wave energy and convert to useful propulsive thrust for a merchant ship.

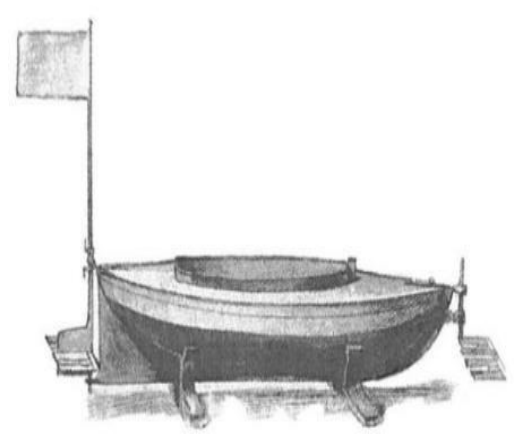

(a) Linden's design [1]

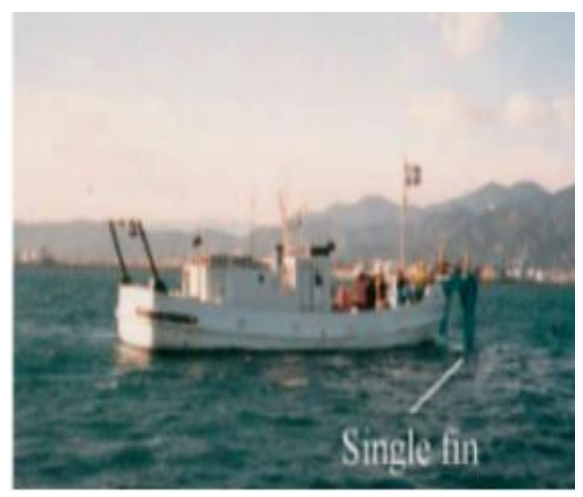

(d) fishing boat with fin [3-5]

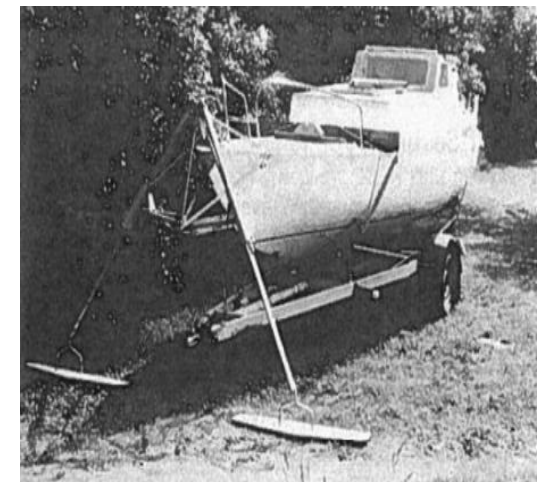

(b) Jakobsen's experimental ship [2]

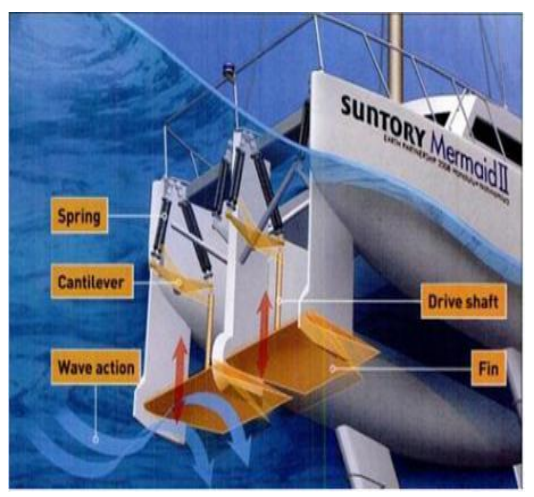

(e) the structure of Mermaid II [6]

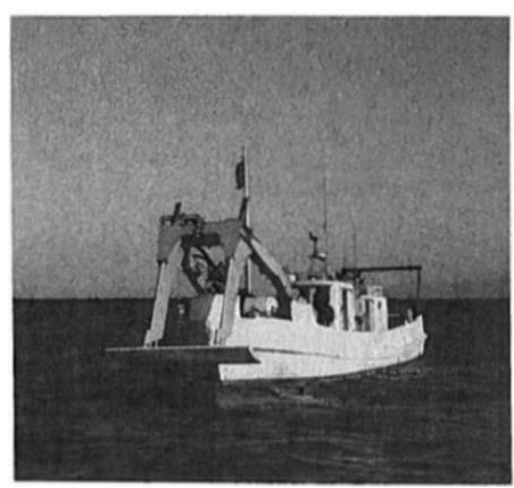

(c) fishing boat with fin [3-5]

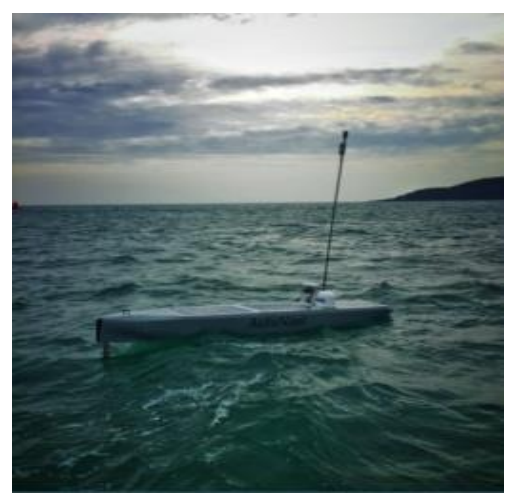

(f) AutoNaut

Fig. 1 Some types of Wave-powered boats

Currently, most researches on wave-powered boats are analyzing the fin's force through fluid analysis software, and there are few dynamic analysis and modeling of wave-powered boats. 
In this paper, the dynamics and propulsion performance of the wave-powered boat were studied. The wave-powered boat was modelled on the basis of multi-body dynamics software ADAMS considering the heaving and pitching motion of boat hull. The relationship among wave condition, stiffness coefficient of restoring spring, and the propulsion performance of the wave-powered boat will be analyzed.

\section{Motion of Wave-powered Boats in Wave}

The structure of wave powered boat is illustrated in Fig 2. It is composed by boat hull, fins, restoring spring, and connecting rod. The fin is mounted on the connecting rod of bow and stern of the hull through the shaft. With the excitation of wave, the heave and pitch motion occurs. The motion causes the rotation of fins about their pivots and the propulsion force can be generated.

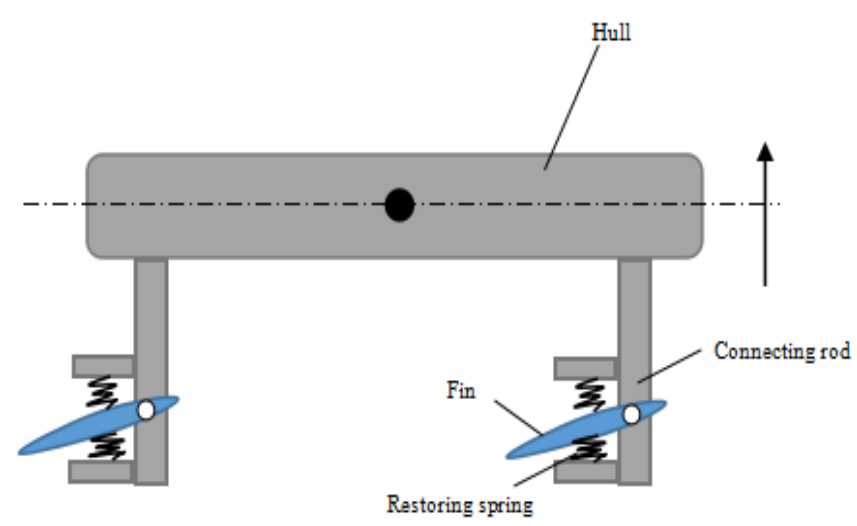

(a) motion of boat under the heave excitation

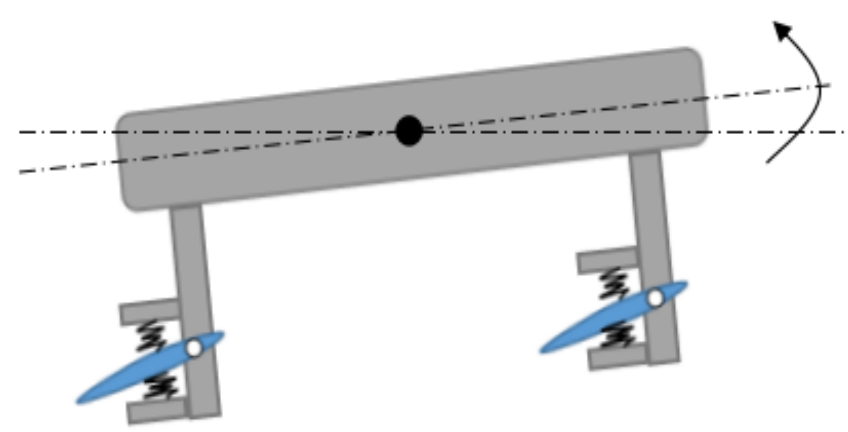

(b) motion of boat under the pitch excitation

Fig 2 Schem atic of the wave powered boat

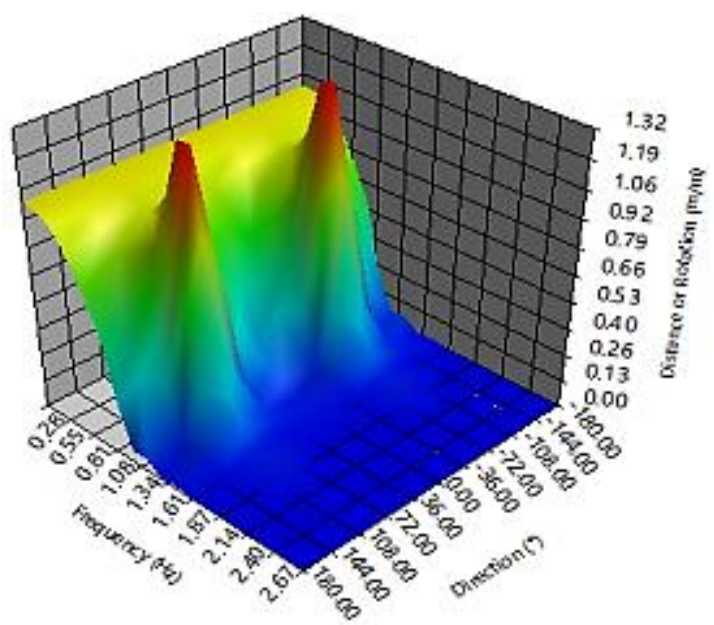

(a) heave direction

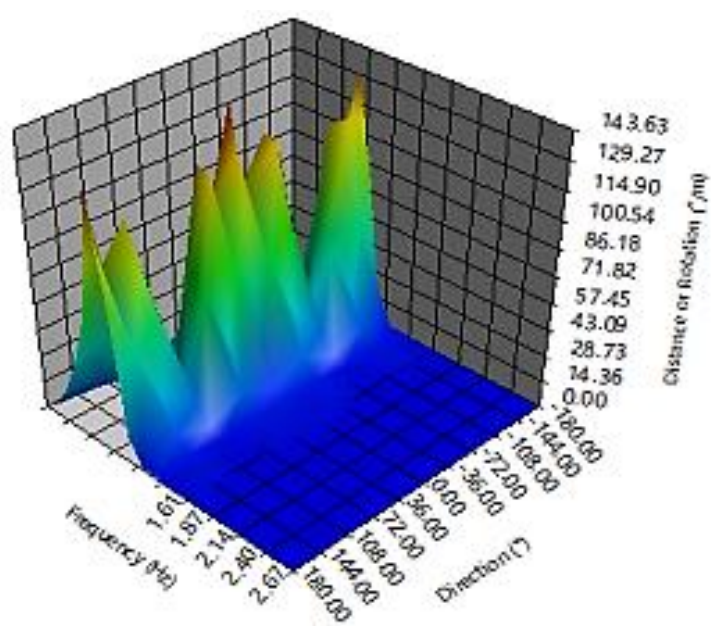

(b) pitch direction

Fig. 3 RAO in heave and pitch direction

The heave and pitch motion of wave powered boat can be calculated by ANSYS-AQWA in frequency domain and time domain. The Response Amplitude Operator (RAO) of the wave-powered boats was obtained in heave and pitch direction (as shown in Fig. 3). In the heave direction, the RAO decreases with the increase of frequency regardless of the incident direction. As the wave direction is consistent with the front and rear directions of the boat, the RY response is obvious.

Then the model of wave-powered boat was imported into the hydrodynamic time response module of ANSYS-AQWA the response of boat hull in time domain can be calculated in different sea states (as shown in Table 1). According to the results, in different sea states, the motion of the hull can be simplified as simple harmonic motion, as shown in Table 2. 
Table 1 Wave paramters of typical sea states

\begin{tabular}{lcc}
\hline & Wave height $\mathrm{A}(\mathrm{m})$ & Wave period $\mathrm{T}(\mathrm{s})$ \\
\hline Level 1 & 0.2 & 1.88 \\
Level 2 & 0.5 & 2.923 \\
Level 3 & 0.68 & 3.5 \\
Level 4 & 1.25 & 4.622 \\
\hline
\end{tabular}

Table 2 The heave and pitch motion of the hull

\begin{tabular}{ccc}
\hline & Heave & Pitch \\
\hline Case 1 & $0.08205 \cdot \operatorname{Sin}(3.302 \cdot \mathrm{t}+1.158)$ & $0.1417 \cdot \operatorname{Sin}(3.302 \cdot \mathrm{t}-0.4272)$ \\
Case 2 & $0.2429 \cdot \operatorname{Sin}(2.176 \cdot \mathrm{t}+1.036)$ & $0.1274 \cdot \operatorname{Sin}(2.176 \cdot \mathrm{t}-0.5384)$ \\
Case 3 & $0.3355 \cdot \operatorname{Sin}(1.751 \cdot+0.9223)$ & $0.1221 \cdot \operatorname{Sin}(1.751 \cdot \mathrm{t}-0.6017)$ \\
Case 4 & $0.6626 \cdot \operatorname{Sin}(1.471 \cdot \mathrm{t}+0.3435)$ & $0.1204 \cdot \operatorname{Sin}(1.471 \cdot \mathrm{t}-1.226)$ \\
\hline
\end{tabular}

\section{Dynamics Analysis of Wave Powered Boat}

\subsection{Hydrodynamic force on fins}

Firstly, the hypothesis was made: ignore the motion of the boat in the transfer plane and establish the motion model of the whole system in the longitudinal plane so that the buoyancy center and the center of mass of each part are in the same vertical plane. The force on the surface of the fin was simplified as the force on the center of mass. The eddy current and wake generated by the fin rotation and the additional mass force was neglected.

Wave-powered boats move with waves. When the boat moves upward, the fins rotate counterclockwise under the action of hydrodynamic force in order that the hydrodynamic force perpendicular to the fins can be decomposed into a vertical downward force and a horizontal forward force. Similarly, when the boat moves downward, the fins rotate clockwise under the action of hydrodynamic force, which is perpendicular to the flow of the fins. Force can be decomposed into a vertical upward force and a horizontal forward force. Thus, no matter the wave-powered boat moves upward or downward, the horizontal forward force generated by the front and rear pairs of wings can push the boat forward.

The model of wave powered boat is shown in Fig. 4. $O_{s}-X_{s} Y_{s}$ is the absolute frame on wave-free sea level; $O_{v}-X_{v} Y_{v}$ is the frame fixed on on the hull; $O_{v 1}-X_{v 1} Y_{v 1}$ and $O_{v 2}-X_{v 2} Y_{v 2}$ represent the coordinate system of bow and stern fin of the boat. The generalized coordinates defined as $X_{s}, Y_{s}, \theta_{v}, \theta_{f 1}, \theta_{f 2}$. $X_{f}, Y_{f}$ are displacement of the center of the hull in $\mathrm{x}$ direction and $\mathrm{y}$ direction. $\theta_{v}$ is the pitch angle of the hull and $\theta_{f 1}, \theta_{f 2}$ are the rotating angle of the fin relative to the local frame $O_{v 1}-X_{v l} Y_{v l}$ and $O_{v 2}-X_{v 2} Y_{v 2} . L_{1}$ is the vertical distance from the center of the boat to the fin pole; $L_{2}$ is the vertical distance from the connecting point between the fin and the pole to the center line of the boat; $L_{3}$ is the length of the fin. Therefore, the position of the boat center in the system coordinate is:

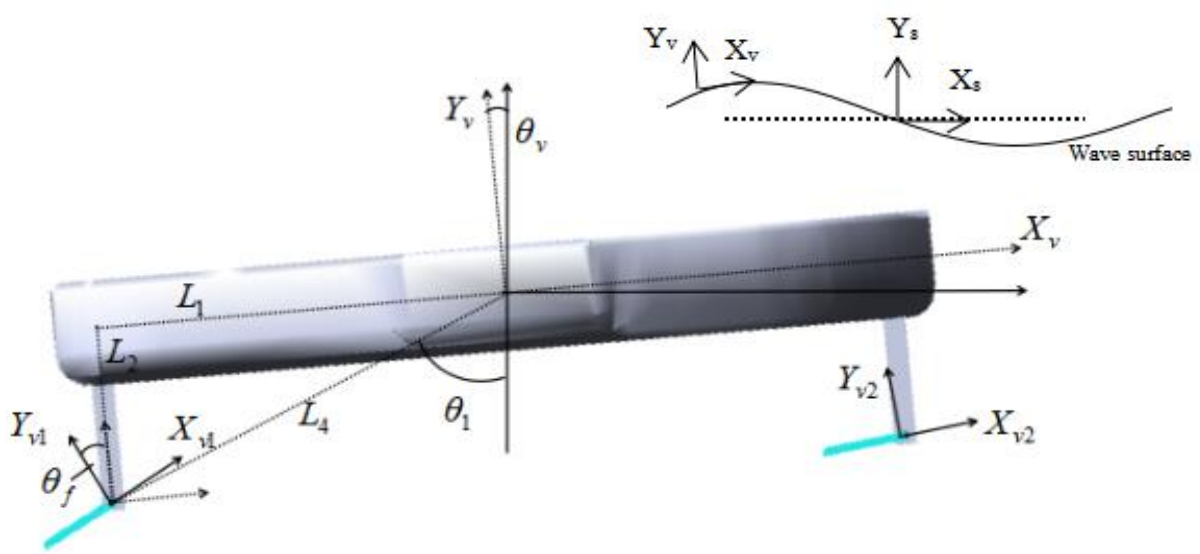

Fig. 4 Model of the wave-powered boat 


$$
\left[\begin{array}{l}
X_{s} \\
Y_{s}
\end{array}\right]
$$

The center position of the bow fin in the system coordinate system is:

$$
\left[\begin{array}{c}
X_{f_{2}} \\
Y_{f_{2}}
\end{array}\right]=\left[\begin{array}{c}
X_{s}-L_{4} \operatorname{Cos} \theta_{2}-L_{3} \operatorname{Cos}\left(\theta_{f_{2}}+\theta_{v}\right) \\
Y_{s}-L_{4} \operatorname{Sin} \theta_{2}-L_{3} \operatorname{Sin}\left(\theta_{f_{2}}+\theta_{v}\right)
\end{array}\right]
$$

The center position of the stern fin in the system coordinate system is:

$$
\left[\begin{array}{c}
X_{f_{1}} \\
Y_{f_{1}}
\end{array}\right]=\left[\begin{array}{c}
X_{s}-L_{4} \operatorname{Cos} \theta_{1}-L_{3} \operatorname{Cos}\left(\theta_{f_{1}}+\theta_{v}\right) \\
Y_{s}-L_{4} \operatorname{Sin} \theta_{1}-L_{3} \operatorname{Sin}\left(\theta_{f_{1}}+\theta_{v}\right)
\end{array}\right]
$$

The combined force of gravity and buoyancy on the boat is,

$$
F_{b}=-m g+\rho S(y+\Delta y) g
$$

The resistance force of boat to water is,

$$
F_{r}=0.5 \rho C S u_{1}^{2}
$$

where $S$ is the area under stress, $\rho$ is the density of seawater, $C$ is the hydrodynamic coefficient, and $u_{l}$ is the forward speed. The rear fin is subjected to $F_{f i n 1-x}$ and $F_{f i n 1-y}$; the front fin is subjected to $F_{f i n 2-x}$ and $F_{f i n 2-y}$. In order to obtain $F_{f i n}$, the fin velocity obtained from the previous analysis is first transferred to the fin-coordinate system:

$$
\begin{aligned}
& {\left[\begin{array}{c}
V_{b_{2}} \\
V_{n_{2}}
\end{array}\right]=\left[\begin{array}{cc}
\operatorname{Cos}\left(-\theta_{f_{2} v}\right) & -\operatorname{Sin}\left(-\theta_{f_{2} v}\right) \\
\operatorname{Sin}\left(-\theta_{f_{2} v}\right) & \operatorname{Cos}\left(-\theta_{f_{2} v}\right)
\end{array}\right]\left[\begin{array}{c}
\dot{X}_{f_{2}} \\
\dot{Y}_{f_{2}}
\end{array}\right]} \\
& {\left[\begin{array}{c}
V_{b_{1}} \\
V_{n_{1}}
\end{array}\right]=\left[\begin{array}{cc}
\operatorname{Cos}\left(-\theta_{f_{1} v}\right) & -\operatorname{Sin}\left(-\theta_{f_{1} v}\right) \\
\operatorname{Sin}\left(-\theta_{f_{1} v}\right) & \operatorname{Cos}\left(-\theta_{f_{1} v}\right)
\end{array}\right]\left[\begin{array}{c}
\dot{X}_{f_{1}} \\
\dot{Y}_{f_{1}}
\end{array}\right]}
\end{aligned}
$$

simplify the hydrodynamics of the fins:

$$
F_{\text {fin }}=-0.5 s \rho C\left[\begin{array}{c}
V_{b} \\
V_{n}
\end{array}\right]
$$

Among them, $s$ is the projection area of the fin; $\rho$ is the density of seawater; and $C$ is the hydrodynamic coefficient. Generally speaking, the forces on the fin are usually divided into tangential and normal forces, and the tangential component is usually much smaller than the normal component. Therefore, in the calculation process, we neglect it, that is, $F_{f i n-x}$ is regarded as zero:

$$
\begin{aligned}
& {\left[\begin{array}{c}
F_{x_{1}} \\
F_{y_{1}}
\end{array}\right]=\left[\begin{array}{cc}
\operatorname{Cos} \theta_{f_{1} v} & -\operatorname{Sin} \theta_{f_{1} v} \\
\operatorname{Sin}-\theta_{f_{1} v} & \operatorname{Cos} \theta_{f_{1} v}
\end{array}\right]\left[\begin{array}{c}
0 \\
F_{f i n_{1}-y}
\end{array}\right]=\left[\begin{array}{c}
-\operatorname{Sin} \theta_{f_{1} v} F_{f i n_{1}-y} \\
\operatorname{Cos} \theta_{f_{1} v} F_{f i n_{1}-y}
\end{array}\right]} \\
& {\left[\begin{array}{l}
F_{x_{2}} \\
F_{y_{2}}
\end{array}\right]=\left[\begin{array}{cc}
\operatorname{Cos} \theta_{f_{2} v} & -\operatorname{Sin} \theta_{f_{2} v} \\
\operatorname{Sin}-\theta_{f_{2} v} & \operatorname{Cos} \theta_{f_{2} v}
\end{array}\right]\left[\begin{array}{c}
0 \\
F_{f i n_{2}-y}
\end{array}\right]=\left[\begin{array}{c}
-\operatorname{Sin} \theta_{f_{2} v} F_{f i n_{2}-y} \\
\operatorname{Cos} \theta_{f_{2} v} F_{f i n_{2}-y}
\end{array}\right]}
\end{aligned}
$$

Substituting $F_{\text {fin-y }}$ and Simplified the force 


$$
\begin{aligned}
& {\left[\begin{array}{l}
F_{x_{1}} \\
F_{y_{1}}
\end{array}\right]=-0.5 \operatorname{s} \rho C\left[\begin{array}{l}
-\operatorname{Sin} \theta_{f_{1} v}\left[\operatorname{Cos} \theta_{f_{1} v} u_{2}-\operatorname{Sin} \theta_{f_{1}} u_{1}-L_{3}\left(u_{3}+u_{4}\right)-L_{4} u_{3} \operatorname{Sin}\left(\theta_{f_{1} v}+\theta_{1}\right)\right] \\
\operatorname{Cos} \theta_{f_{1} v}\left[\operatorname{Cos} \theta_{f_{1} v} u_{2}-\operatorname{Sin} \theta_{f_{1} v} u_{1}-L_{3}\left(u_{3}+u_{4}\right)-L_{4} u_{3} \operatorname{Sin}\left(\theta_{f_{1} v}+\theta_{1}\right)\right]
\end{array}\right]} \\
& {\left[\begin{array}{l}
F_{x_{2}} \\
F_{y_{2}}
\end{array}\right]=-0.5 \operatorname{s} \rho C\left[\begin{array}{l}
-\operatorname{Sin} \theta_{f_{2} v}\left[\operatorname{Cos} \theta_{f_{2} v} u_{2}-\operatorname{Sin} \theta_{f_{2} v} u_{1}-L_{3}\left(u_{3}+u_{5}\right)-L_{4} u_{3} \operatorname{Cos}\left(\theta_{f_{2} v}+\theta_{2}\right)\right] \\
\operatorname{Cos} \theta_{f_{2} v}\left[\operatorname{Cos} \theta_{f_{2} v} u_{2}-\operatorname{Sin} \theta_{f_{2} v} u_{1}-L_{3}\left(u_{3}+u_{5}\right)-L_{4} u_{3} \operatorname{Sin}\left(\theta_{f_{2} v}+\theta_{2}\right)\right]
\end{array}\right]}
\end{aligned}
$$

\subsection{Simulation and results}

Based on the above method, the model of the wave-powered boat (Fig. 5) is established in multi-body dynamics software ADAMS. The forces acting on the fins are calculated according to Eq. (9), and the resistant force on the boat are calculated according to Morison Formulation. The restoring moment $\left(M_{\text {spring }}=K \cdot \theta_{f}\right)$ on fin can be obtained by the rotation angle and the restoring spring coefficient. The mainly parameters of the boat are shown in Table 3. The propulsion displacement and velocity of the wave-powered boat under different sea state are shown in Fig. 6. It can be seen that with the increase of wave conditions, the boat's forward speed increases, and the velocity fluctuation becomes larger.

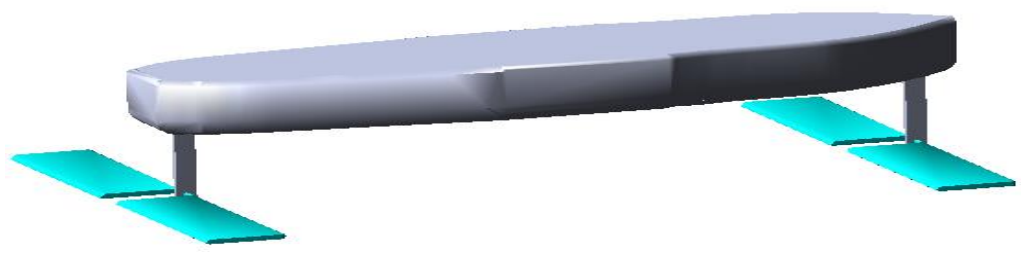

Fig. 5 Models of Wave-powered boat in ADAMS

Table 3 Parameters used in the simulation of wave-powered boat

\begin{tabular}{cc}
\hline Parameter & Value \\
\hline Weight of Wave-powered Boat $(\mathrm{kg})$ & 40 \\
Width of the boat $(\mathrm{m})$ & 0.5 \\
Height of the boat $(\mathrm{m})$ & 0.25 \\
Length of the boat $(\mathrm{m})$ & 2 \\
Restoring Stiffness K of Torsional Spring $(\mathrm{N} \cdot \mathrm{m} / \mathrm{deg})$ & 0.1 \\
Thickness of the fin $(\mathrm{m})$ & 0.02 \\
Width of the fin $(\mathrm{m})$ & 0.2 \\
Length of the fin $(\mathrm{m})$ & 0.6 \\
\hline
\end{tabular}

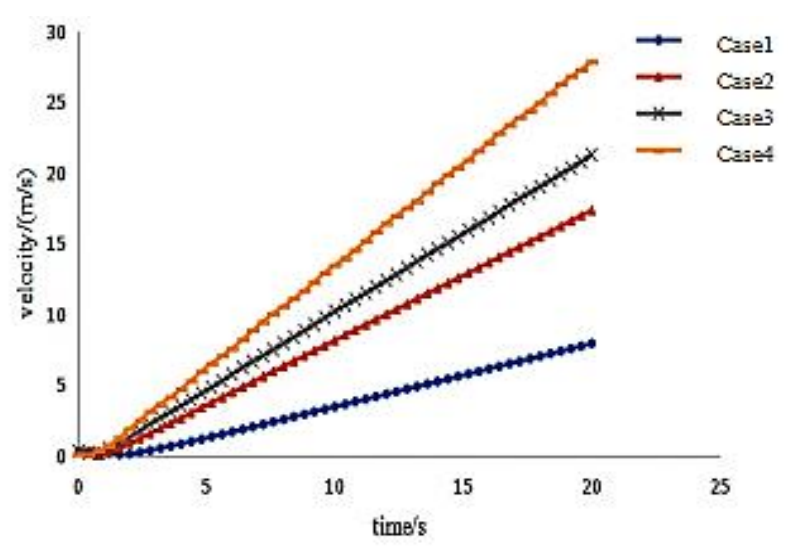

(a) displacement

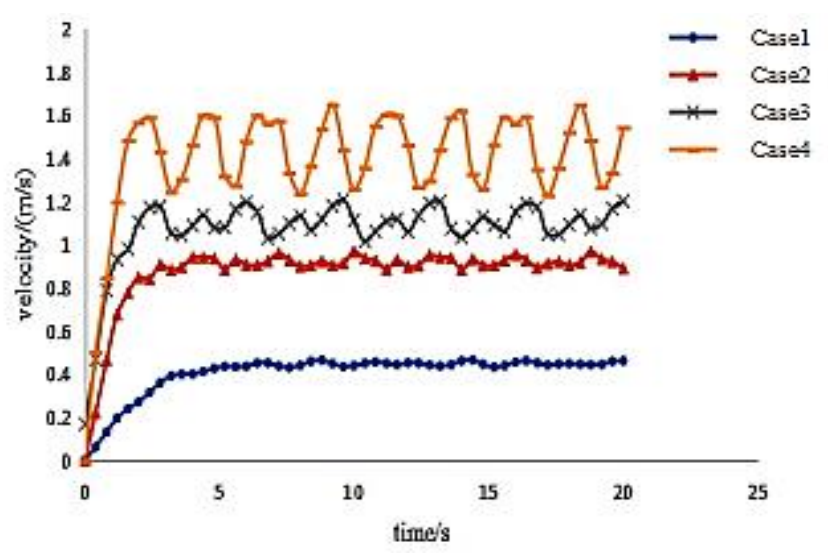

(b) Velocity

Fig. 6 Response of wave powered boat under different sea conditions

At the same time, the effects of stiffness coefficient of restoring spring on propulsion performance are analyzed. The velocities of the boat with different stiffness coefficient are shown in Fig. 7. Fig 7(a) presents the maximum propulsion speed is $0.6 \mathrm{~m} / \mathrm{s}$ at the stiffness of $0.025 \mathrm{~N} . \mathrm{m} / \mathrm{deg}$, and the average velocity is about $0.54 \mathrm{~m} / \mathrm{s}$ in case 1 . Fig. 7 (b) shows that under the 
case 2, the maximum propulsion speed is $1 \mathrm{~m} / \mathrm{s}$ when the stiffness is $0.05 \mathrm{~N} . \mathrm{m} / \mathrm{deg}$, and the average speed is about $0.89 \mathrm{~m} / \mathrm{s}$. Fig. $7(\mathrm{c})$ indicates that under the case 3, the maximum propulsion speed is $1.21 \mathrm{~m} / \mathrm{s}$, and the average speed is about $1.08 \mathrm{~m} / \mathrm{s}$ when the stiffness of wave-powered boat is $0.2 \mathrm{~N} . \mathrm{m} / \mathrm{deg}$. Fig.7(d) illustrates that under the case 4 , the maximum propulsion speed is $1.65 \mathrm{~m} / \mathrm{s}$, and the average speed is about $1.4 \mathrm{~m} / \mathrm{s}$ when the stiffness of wave-powered boat is 0.2 N.m/deg.

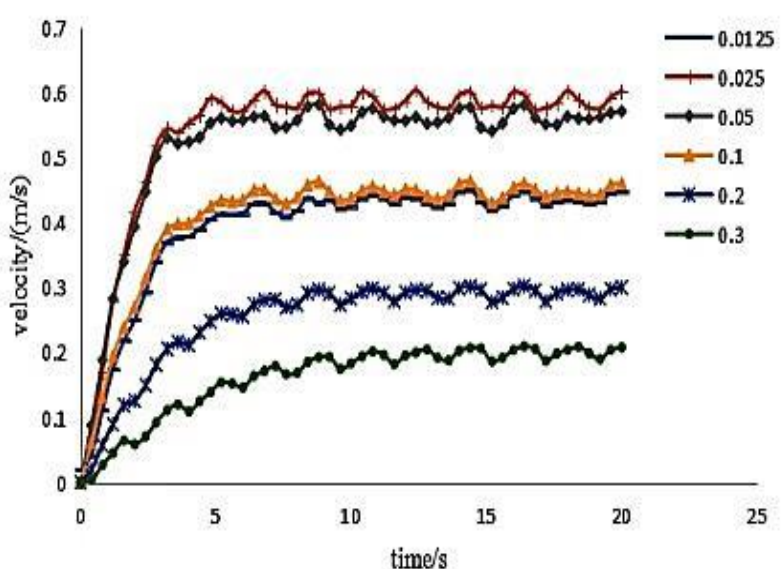

(a) case 1

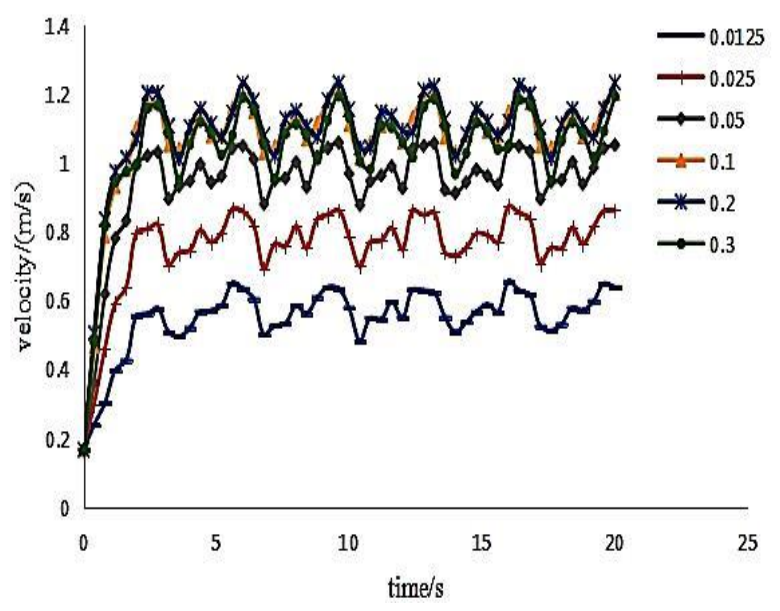

(c) case 3

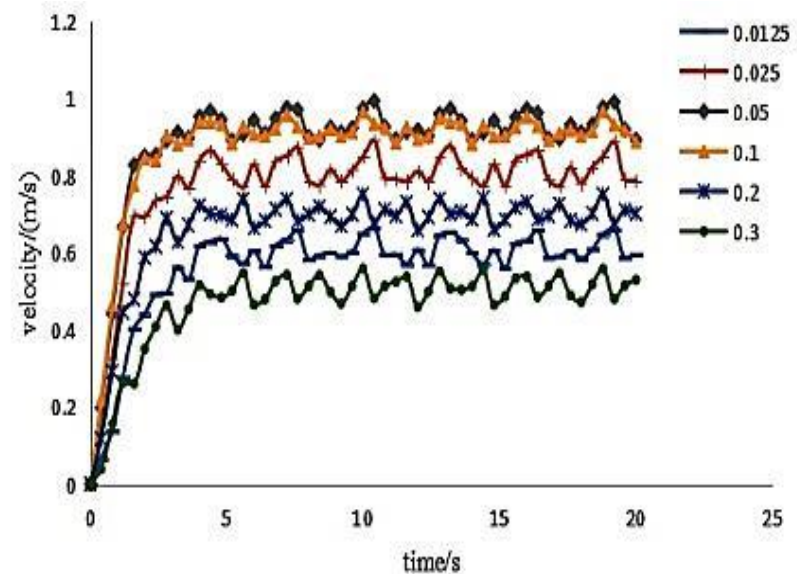

(b) case 2

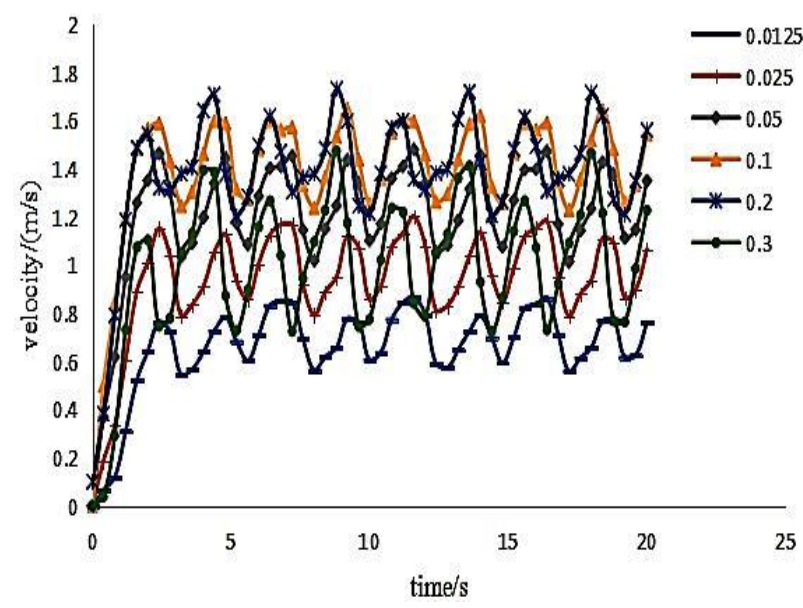

(d) case 4

Fig. 7 Simulations of different restoring stiffness of torsion spring under the same case

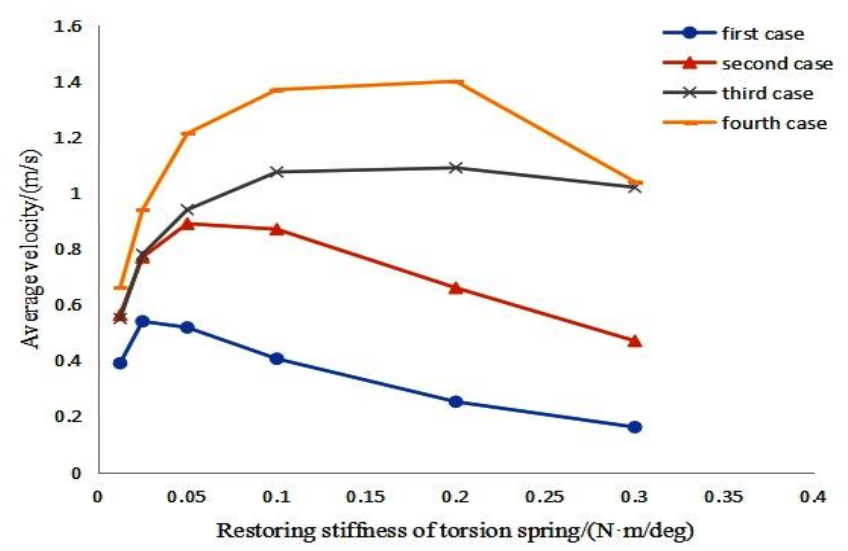

Fig. 8 Relation ship between sea state, coefficient of stiffness and average propulsion velocity

Fig. 8 illustrates the effects of stiffness coefficient on the propulsion velocity of wave powered boat. It can be seen that the optimum restoring stiffness of torsion spring increases with the increase of wave conditions generally. Among them, when the stiffness of the case 1 is about $0.025 \mathrm{~N} . \mathrm{m} / \mathrm{deg}$, the average propulsion speed reaches the highest; the average propulsion speed reaches its maximum when the stiffness of the case 2 is about $0.05 \mathrm{~N} . \mathrm{m} / \mathrm{deg}$. When the stiffness of the case 3 and case 4 are around $0.1 \mathrm{~N} . \mathrm{m} / \mathrm{deg}$, the average propulsion speed reaches the highest. 


\section{Conclusions}

In this paper, the dynamic behavior and propulsion performance of the wave-powered boat were studied under the heave and pitch motion of boat hull. The motion and RAO were firstly calculated by AQWA. The multibody model of the wave-powered boat was established in ADAMS. The relationship between wave parameters and design parameters of boat and propulsion performance was analyzed. Some conclusions were obtained as follow.

(1) Dynamical model of the wave-powered boat under the combined motion of heave and pitch is developed and the propulsion performance is analyzed.

(2) The sea state has obvious effects on the propulsion speed of the wave powered boat. With the increase of the sea state, the speed of propulsion increases obviously. Actually, wave height and wave period were the key factors to affect the propulsion.

(3) The parameter of restoring stiffness of fin was another important factor. With the change of restoring stiffness, the propulsion speed of the wave-powered boat varied with complex manner. But the optimum stiffness of torision spring can be calculated and selected with different wave parameters and design parametners.

\section{Acknowledge}

The authors are grateful for the financial support of National Science Foundation of China (No. 51875540)

\section{Conflicts of Interest}

The authors declare no conflict of interest.

\section{References}

[1] H. Linden, Improved combination with floating bodies, of fins adapted to affect their propulsion, U. S. Patent, 14630, 1895.

[2] E. Jakobsen, The foil propeller, wave power for propulsion, U. S. Patent, 1981.

[3] H. Isshiki, M. Murakami, and Y. Terao, "Utilization of wave energy into propulsion of ships-wave devouring propulsion," 15th Symposium on Naval Hydrodynamics, Hamburg, September 1984, pp. 539-552.

[4] Y. Terao and N. Sakagami, "Design and development of an autonomous wave-powered boat with a wave devouring propulsion system,” Advanced Robotics, vol. 29, no. 1, pp. 89-102, January 2015.

[5] Y. Terao, "A floating structure which moves toward the waves : possibility of wave devouring propulsion," Journal of the Kansai Society of Naval Architects Japan, vol. 57, pp. 51-54, 1982.

[6] H. Isshiki, M. Murakami, and Y. Terao, "Thrust generation by a hydrofoil driven by waves: a basic aspect of wave devouring propulsion," Hydrodynamics of Ocean Wave-Energy Utilization, pp. 227-236, 1986.

[7] Y. Terao, "Wave devouring propulsion system: from concept to trans-pacific voyage," ASME 2009 International Conference on Ocean, Offshore and Arctic Engineering, January 2009, pp. 119-126.

[8] K. A. Belibassakis and G. K. Politis, "Hydrodynamic performance of flapping wings for augmenting ship propulsion in waves,” Ocean Engineering, vol. 72, no. 4, pp. 227-240, November 2013.

[9] K. A. Belibassakis and E. S. Filippas, "Ship propulsion in waves by actively controlled flapping foils," Applied Ocean Research, vol. 52, pp. 1-11, August 2015.

[10] C. Li, D. J. Wang, J. W. Ye, D. Y. Li, and F. Liang, "Free running model tests and numerical simulation on a wave propelled craft," Chinese Journal of Ship Research, vol. 9, no. 2, pp. 6-11, April 2014.

[11] C. Li, "Experimental research on a wave propelled craft," M.S. dissertation, South China University of Technology, Guangzhou, 2014.

[12] Y. Y. Zheng, "The research on the hydrodynamic performance of wave energy propelled unmanned observation catamaran," M. S. dissertation, South China University of Technology, Guangzhou, 2015.

[13] M. X. Zhu, N. Ma, X. C. Gu, and S. J. University, "Study on wave motion and added resistance of a ship with hydrofoils assisting propulsion," Ship Engineering, vol. 36, no. 2, pp. 20-24, 2014. 
[14] P. Y. Feng, N. Ma, and X. C. Gu, "Application of wave energy recovery by oscillating wings in Energy-efficient ship propulsion,” Journal of Shanghai Jiao Tong University, vol. 47, no. 6, pp. 923-927, June 2013.

[15] Z. X. Feng, Z. Y. Chang, Z. Q. Zheng, and P. F. Wang, "Effects of connection type between surface vessel and submersible propeller on motion performance of wave glider," Applied Sciences, vol. 8, no. 12, pp. 2467, December 2018.

[16] X. X. Du, H. Cui, and Z. H. Xiang, "The multi-body system dynamics modeling of wave-driven underwater vehicle based on kane method," Acta Armamentarii, vol. 37, no. 7, pp. 1236-1244, July 2016.

[17] B. Q. Tian and L. L. Li, "Structure design and movement principle of wave gliders with webbed wings," China Mechanical Engineering, vol. 28, no. 24, pp. 2939-2943, July 2017.

[18] K. Suastika and Apriansyah, "Effects of stern-foil submerged elevation on the lift and drag of a hydrofoil craft," IOP Conference Series Earth and Environmental Science, vol 135, no. 1, pp. 012003, March 2018.

[19] J. A. Bowker, N. C. Townsend, and M. Tan, "Experimental study of a wave energy scavenging system onboard autonomous surface vessels," Oceans, Genova, May 2015.

[20] W. A. D. S. Liyanarachchi and H. Yamaguchi, "Numerical study on active wave devouring propulsion," Journal of Marine Science and Technology, vol. 17, no. 3, pp. 261-275, September 2012.

[21] F. C. Chiu, W. F. Li, and W. C. Tiao, "Preliminary study on a concept of wave propulsion by an active pitch-oscillating fin," Oceans, Taipei, November 2014.

[22] S. W. Huang, T. L. Wu, and Y. T. Hsu, "Effective energy-saving device of Eco-Ship by using wave propulsion," Techno-Ocean, Japan, October 2016.

Copyright $\odot$ by the authors. Licensee TAETI, Taiwan. This article is an open access article distributed under the terms and conditions of the Creative Commons Attribution (CC BY-NC) license (https://creativecommons.org/licenses/by-nc/4.0/). 